\title{
Clinical Appearance of Oral Candida Infection and Therapeutic Strategies
}

\author{
Shankargouda Patil' ${ }^{\star}$, Roopa S. Rao', Barnali Majumdar' and Sukumaran Anil'² \\ ${ }^{1}$ Department of Oral Pathology and Microbiology, Faculty of Dental Sciences, M. S. Ramaiah University of Applied Sciences, \\ Bangalore, India, ${ }^{2}$ Dental Biomaterials Research Chair, Dental Health Department, College of Applied Medical Sciences, \\ King Saud University, Riyadh, Saudi Arabia
}

Candida species present both as commensals and opportunistic pathogens of the oral cavity. For decades, it has enthralled the clinicians to investigate its pathogenicity and to improvise newer therapeutic regimens based on the updated molecular research. Candida is readily isolated from the oral cavity, but simple carriage does not predictably result in development of an infection. Whether it remains as a commensal, or transmutes into a pathogen, is usually determined by pre-existing or associated variations in the host immune system. The candida infections may range from non-life threatening superficial mucocutaneous disorders to invasive disseminated disease involving multiple organs. In fact, with the increase in number of AIDS cases, there is a resurgence of less common forms of oral candida infections. The treatment after confirmation of the diagnosis

OPEN ACCESS

Edited by: Chaminda Jayampath Seneviratne, National University of Singapore,

Singapore

Reviewed by:

Zaw Moe Thein,

Ministry of Health, Myanmar Ruwan Duminda Jayasinghe, University of Peradeniya, Sri Lanka

*Correspondence: Shankargouda Patil sbpatil1612@gmail.com

Specialty section: This article was submitted to Antimicrobials, Resistance and Chemotherapy, a section of the journal Frontiers in Microbiology

Received: 31 August 2015 Accepted: 23 November 2015 Published: 17 December 2015

Citation:

Patil S, Rao RS, Majumdar B and Anil S (2015) Clinical Appearance of Oral Candida Infection and Therapeutic Strategies.

Front. Microbiol. 6:1391. doi: 10.3389/fmicb.2015.01391 should include recognizing and eliminating the underlying causes such as ill-fitting oral appliances, history of medications (antibiotics, corticosteroids, etc.), immunological and endocrine disorders, nutritional deficiency states and prolonged hospitalization. Treatment with appropriate topical antifungal agents such as amphotericin, nystatin, or miconazole usually resolves the symptoms of superficial infection. Occasionally, administration of systemic antifungal agents may be necessary in immunocompromised patients, the selection of which should be based upon history of recent azole exposure, a history of intolerance to an antifungal agent, the dominant Candida species and current susceptibility data.

Keywords: antifungal therapy, Candida, NCAC species, oral candidosis, opportunistic infections

\section{INTRODUCTION}

The malady of thrush or candidiasis has been known to occur in people for over 2000 years. As mentioned by the famous Greek physician, Hippocrates in his findings, it commonly presents as superficial infections of the oral and vaginal mucosa. However, it was not until the mid-1800s that the documented research on pathogenesis of candidiasis were instigated. The principal yeast pathogen, Candida albicans, itself, was identified in the nineteenth century. In the early 1900s, C. albicans was found in the oral cavity of 54\% of 2-6 weeks old and $46 \%$ of 1 year old infants and in 39\% of 1-6 years old children, nonetheless several of them were rather healthy (Barnett, 2008). It was only later, that the subsequent studies revealed the normal oral carriage of C. albicans is 2.0$69.1 \%$ among the healthy adult population, depending upon the sampled population and technique (Scully et al., 1994).

In recent years, noteworthy escalation in pathogenic state of this commensal has been observed, as reflected in the increased incidence of the common and infrequent forms of candidiasis 
(Williams and Lewis, 2011). The probable explanations include changes in the practice of medicine like introduction of broad-spectrum antibiotics, immunosuppressive agents, transplantations, indwelling catheters, etc., and morbid conditions such as diabetes, severe malnutrition in children and AIDS (Lalla et al., 2013). Oral candidiasis is a significant source of morbidity, as it can cause chronic pain or discomfort upon mastication, limiting nutrition intake in the elderly or immunodeficient patients. There are multiple clinical presentations of oropharyngeal and esophageal candidiasis caused by $C$. albicans, either alone or in mixed infection (Sherman et al., 2002). Thus, with the above outlook, the present review comprehends the varied clinical manifestations and the current treatment strategies for this opportunistic pathogen.

\section{EPIDEMIOLOGY}

Oral candidosis is frequent in the extremes of age (Akpan and Morgan, 2002). Approximately 5-7\% of infants develop oral candidiasis. Its prevalence in AIDS patients is estimated to be 9$31 \%$ and close to $20 \%$ in the cancer patients (Lalla et al., 2013). The oral carriage of candida organisms is reported to be 30$45 \%$ in the general healthy adult population (Akpan and Morgan, 2002). The incidence of C. albicans in healthy and various health conditions is depicted in Table 1. The additional important species isolated from clinical infections include, C. glabrata, C. guillierimondii, C. krusei, C. lusitaniae, C. parapsilosis, C. pseudotropicalis, C. stellatoidea, and C. tropicalis (Crist et al., 1996). In recent years higher incidences of the above mentioned non- C. albicans Candida (NCAC) species have been also reported (Williams and Lewis, 2011).

Systemic candidiasis is less frequent but carries a mortality rate of $71-79 \%$. The annual incidence of bloodstream infection (BSI) associated with candida ranges from 6-23/100,000 to 2.53-11/100,000 individuals in USA and European countries, respectively. Overall NCAC species have shown an increasing trend as causative pathogens in BSIs with a $10-11 \%$ increment over a 6.5-year period in a global report. In addition to C. albicans, the common NCAC species involved in BSIs include C. parapsilosis (premature neonates and catheterized patients); C. glabrata (elderly patients); C. tropicalis (hematological malignancies); and C. krusei (Richardson, 2005).

TABLE 1 | Oral carriage of Calbicans albicans in various subjects (Akpan and Morgan, 2002).

\begin{tabular}{ll}
\hline Subjects & Oral carriage of C. albicans \\
\hline Neonates & $45 \%$ \\
Healthy children & $45-65 \%$ \\
Healthy adults & $30-45 \%$ \\
Removable denture wearers & $50-65 \%$ \\
Long term facilities & $65-88 \%$ \\
Acute leukemia undergoing chemotherapy & $90 \%$ (approximately) \\
HIV patients & $95 \%$ (approximately)
\end{tabular}

\section{FACTORS PREDISPOSING FOR ORAL CANDIDIASIS (TABLE 2)}

\section{Local Factors}

\section{Saliva}

Salivary gland dysfunction predisposes to oral candidiasis. Constituents of saliva such as histidine-rich polypeptides, lactoferrin, lysozyme, and sialoperoxidase inhibit the overgrowth of candida. Hence, conditions affecting the quantity and quality of salivary secretions may lead to an increased risk of oral candidosis (Scully et al., 1994; Turner and Ship, 2007).

\section{Dental Prostheses}

Dental prostheses creates a favorable microenvironment for the candida organisms to thrive. Approximately 65\% of complete denture wearers are predisposed to candida infection. The possible explanations include enhanced adherence of candida to the acrylic, ill-fitted appliances, decreased saliva flow under the denture surfaces or inadequate hygiene (Ashman and Farah, 2005; Martori et al., 2014).

\section{Topical Medications}

Another important local factor increasing the risk of oral candidosis could be use of topical or inhalational corticosteroids and overzealous use of antimicrobial mouthwashes. They temporarily suppress the local immunity and cause alterations in the oral flora (Scully et al., 1994; Jainkittivong et al., 2007).

\section{Smoking}

Some studies suggest that smoking alone or in combination with other factors, significantly affects the oral candida carriage while few studies propose otherwise (Soysa and Ellepola, 2005; Barnett, 2008; Munshi et al., 2015). The precise mechanism is not established but various theories have been postulated. The possible explanations facilitating candida colonization include localized epithelial alterations caused by smoking (Arendorf and Walker, 1980); smoking in association with denture friction altering the mucosal surface (Arendorf and Walker, 1987); nutritional products obtained through enzymatic breakdown

TABLE 2 | Factors predisposing for oral candidiasis (Rautemaa and Ramage, 2011).

\begin{tabular}{ll}
\hline Local factors & Systemic factors \\
\hline - Impaired local defense & - Impaired systemic defense mechanisms \\
mechanisms & \\
- Decreased saliva production & - Primary or secondary immunodeficiency \\
- Smoking & - Immunosuppressive medications \\
- Atrophic oral mucosa & - Endocrine disorders- Diabetes \\
- Mucosal diseases (Oral lichen & - Malnutrition \\
planus) & - Malignancies \\
- Topical medications - corticoids & - Congenital conditions \\
- Decreased blood supply & \\
(radiotherapy) & - Broad spectrum antibiotic therapy \\
- Poor oral hygiene & \\
- Dental prostheses &
\end{tabular}


of aromatic hydrocarbons contained in cigarette smoke (Hsia et al., 1981; Krogh et al., 1987); suppression of local immunity and reduction in gingival exudate; elevation of glycosylated hemoglobin levels and lastly tobacco smoke increasing the adrenaline levels in blood, indirectly affecting the blood glucose levels.

\section{Diet}

Unbalanced dietary intake of refined sugars, carbohydrates and dairy products (containing high content of lactose) might serve as growth enhancers by reducing the $\mathrm{pH}$ levels and hence favoring the candida organisms to thrive (Martins et al., 2014).

\section{Systemic Factors \\ Age}

Extremes of age may predispose to candidiasis due to immature or weakened immunity (Weerasuriya and Snape, 2008).

\section{Nutritional Status}

Among the nutritional deficiency states, iron has been the most common deficient essential micronutrient implicated in the colonization of candida. Deficiency of iron diminishes the fungistatic action of transferrin and other iron-dependant enzymes. In addition, other nutrients frequently deficit in chronic candidiasis includes essential fatty acids, folic acid, vitamins A and B6, magnesium, selenium, and zinc (Paillaud et al., 2004; Martins et al., 2014).

\section{Systemic Drugs}

Prolonged use of systemic drugs like broad-spectrum antibiotics, immune-suppressants and drugs with xerostomic side-effects, alter the local oral flora or disrupt mucosal surface or reduce the salivary flow, creating a favorable environment for candida to grow (Martins et al., 2014). Escalation in candida organisms has also been reported in patients undergoing radiation therapy to the head and neck region.

\section{Endocrine Disorders}

Various reports reveal that oral and invasive candidiasis are more prevalent in patients with endocrine dysfunctions such as diabetes and Cushing's syndrome (Graham and Tucker, 1984; Bakker et al., 1998; Sashikumar and Kannan, 2010).

\section{Immune Disorders}

Immunodeficiency conditions such as AIDS and severe combined immunodeficiency syndrome (SCID) are also predisposing factors for candidiasis (Anil and Challacombe, 1997; Owotade and Patel, 2014).

\section{Malignancies}

The host defense mechanisms are compromised by chemotherapy and radiotherapy administered for the treatment of malignant conditions. The prevalence of oral candidiasis for all cancer treatments, according to a systematic review, was reported to be $7.5 \%$ pre-treatment, $39.1 \%$ during treatment and $32.6 \%$ post-cancer therapy. The prevalence of oral candidiasis during head and neck radiation therapy and chemotherapy was observed to be 37.4 and $38 \%$, respectively. The colonization by C. albicans was reported to be $46.2 \%$. The prevalence of NCAC species were C. tropicalis (16.6\%), C. glabrata (5.5\%), and C. krusei (3\%) (Scheffel et al., 2010).

\section{Congenital Conditions}

Lastly, individuals affected by congenital conditions associated with defective immune system such as Di George's syndrome, hereditary myeloperoxidase deficiency and Chediak-Higashi syndrome are commonly predisposed to candida infections (Ashman and Farah, 2005).

\section{FORMS OF ORAL CANDIDA INFECTIONS (TABLE 3)}

\section{Primary Oral Candidiasis Primary Triad \\ Pseudomembranous candidiasis}

This form of candidiasis classically presents as acute infection, though the term chronic pseudomembranous candidiasis has been used to denote chronic recurrence cases. It is commonly seen in extremes of age, immunocompromised patients especially in AIDS, diabetics, patients on corticosteroids, prolonged broad-spectrum antibiotic therapy, hematological, and other malignancies (Figure 1). On the oral surfaces, the superficial component presents as white to whitish-yellow creamy confluent plaques resembling milk curds or cottage cheese. These plaques consist of desquamated epithelial cells, tangled aggregates of fungal hyphae, fibrin, and necrotic material (Lalla et al., 2013). The superficial pseudo-membrane can be removed by wiping gently, leaving behind an underlying erythematous and occasionally bleeding surface (Ashman and Farah, 2005; Farah et al., 2010). The oral surfaces frequently involved include labial and buccal mucosa, tongue, hard and soft palate and oropharynx.

TABLE 3 | Classification of oral candidosis (Axell et al., 1997).

\begin{tabular}{ll}
\hline Primary oral candidosis & Secondary oral candidosis \\
\hline Acute forms & Oral manifestations of systemic \\
& mucocutaneous candidosis \\
Pseudomembranous & Thymic aplasia \\
Erythematous & Candidosis endocrinopathy \\
& syndrome
\end{tabular}

Chronic forms

Hyperplastic (nodular or plaque-like)

Erythematous

Pseudomembranous

Candida-associated lesions

Denture stomatitis

Angular cheilitis

Median rhomboid glossitis

Keratinized primary lesions with

candidal super infection

Leukoplakia

Lichen planus

Lupus erythematosus 


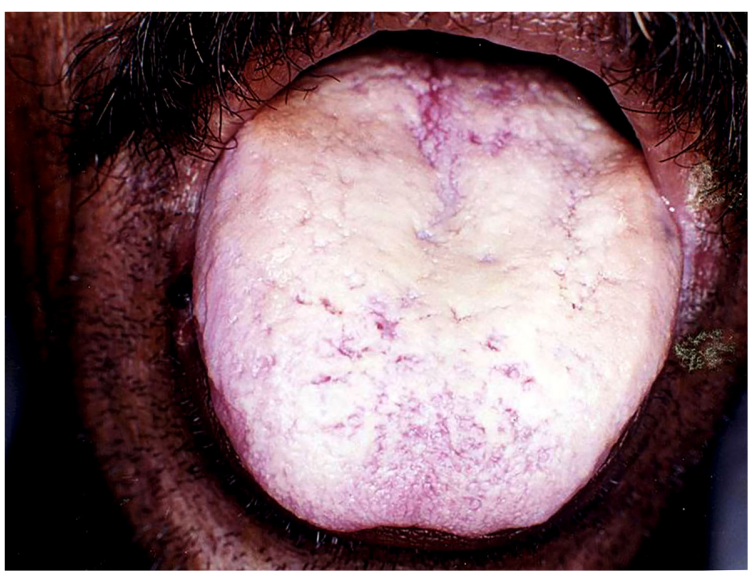

FIGURE 1 | Pseudomembranous candidiasis of the tongue. The copyright of the images is owned by Prof. Anil and a written consent was obtained for the Figures 1-6.

The involvement of both oral and oesophageal mucosa is prevalent in AIDS patients. The symptoms of the acute form are rather mild and the patients may complain only of slight tingling sensation or foul taste, whereas, the chronic forms may involve the oesophageal mucosa leading to dysphagia and chest pains. Few lesions mimicking pseudomembranous candidiasis could be white coated tongue, thermal and chemical burns, lichenoid reactions, leukoplakia, secondary syphilis and diphtheria (Lalla et al., 2013).

\section{Erythematous candidiasis}

Erythematous candidiasis is relatively rare and manifests as both acute and chronic forms (Ashman and Farah, 2005). Previously known as 'antibiotic sore mouth', due to its association with prolonged use of broad-spectrum antibiotics (Farah et al., 2010). The chronic form is usually seen in HIV patients involving the dorsum of the tongue and the palate and occasionally the buccal mucosa (Figure 2). Clinically, it manifests as painful localized erythematous area. It is the only form of candidiasis associated with pain. The lesions are seen on the dorsum of the tongue typically presenting as depapillated areas. Palatal lesions are more common in HIV patients. Differential diagnosis may include mucositis, denture stomatitis, erythema migrans, thermal burns, erythroplakia, and anemia (Dodd et al., 1991).

\section{Hyperplastic candidiasis}

The hyperplastic candidiasis mainly presents as chronic form. It has been commonly referred previously by several authors as 'candidal leukoplakia.' Clinically, it may manifest as one of the two variants; homogeneous adherent white plaque-like or erythematous multiple nodular/speckled type (Holmstrup and Bessermann, 1983; Sanketh et al., 2015). The lesions usually occur bilaterally in the commissural region of the buccal mucosa and less frequently on the lateral border of the tongue and palate (Figure 3). Unlike the pseudomembranous type, hyperplastic candidiasis lesions are non-scrapable. There appears to be a positive association with smoking and in addition may present

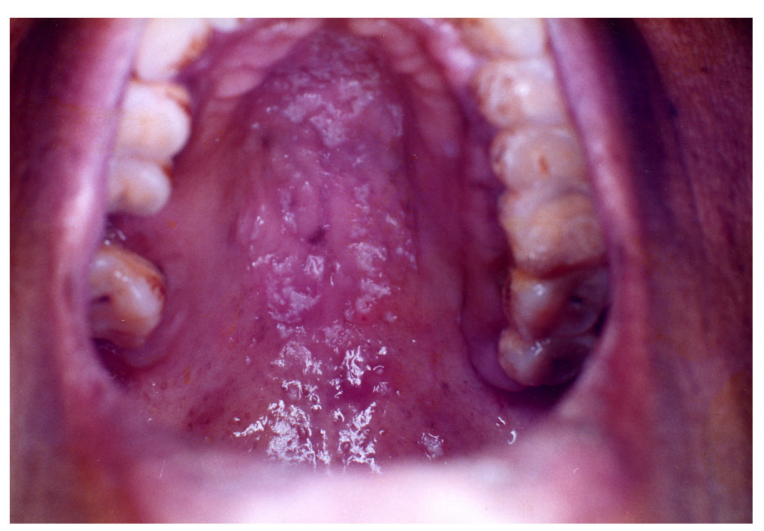

FIGURE 2 | Erythematous candidiasis of the palate.

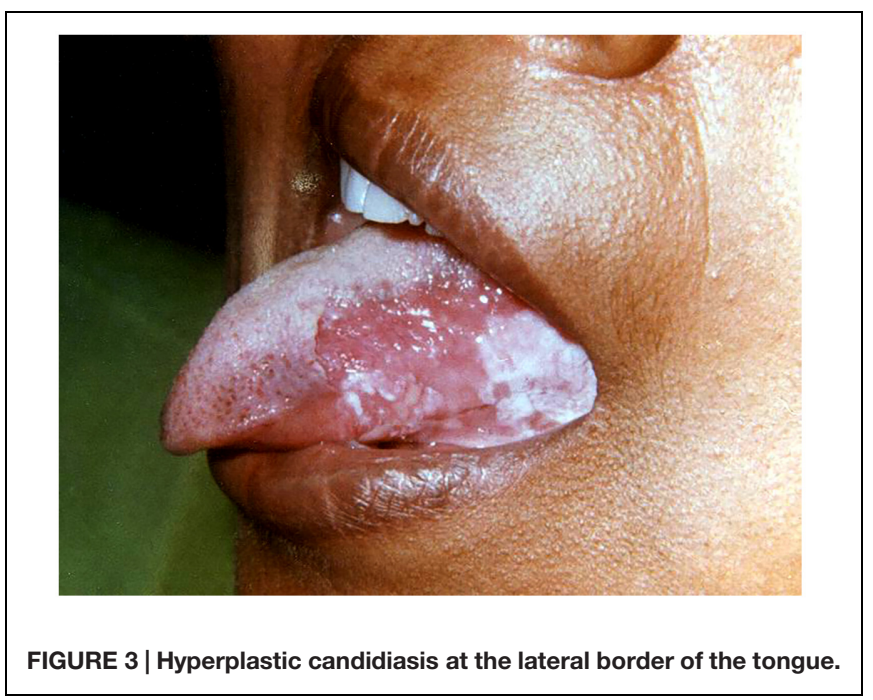

with varying degrees of dysplasia (Williams and Lewis, 2011). A confirmed association between Candida and oral cancer is yet to be recognized, although in vitro studies have shown that the candida organisms can generate carcinogenic nitrosamine (Farah et al., 2010; Sanketh et al., 2015). A small percentage of cases occur in association with iron and folate deficiencies and with defective cell-mediated immunity. Differential diagnosis may include leukoplakia, lichen planus, angular cheilitis and squamous cell carcinoma.

\section{Candida-associated Lesions}

\section{Denture stomatitis}

It is also known as "chronic atrophic candidiasis." As the name indicates, it is chronic inflammation of the mucosa typically restricted to the denture-bearing area, seen in association with candidiasis (Lund et al., 2010). It is seen in almost $50-65 \%$ of the denture wearers (Ashman and Farah, 2005; Williams and Lewis, 2011). Clinically, the lesions may be seen as pinpoint hyperaemia, diffuse erythematous or granular/papillary type. It occurs frequently along with angular cheilitis and median rhomboid glossitis. The lesions are usually asymptomatic, though 
occasionally patients may complain of burning sensation or soreness. It commonly affects the palate although mandibular mucosa may also be affected (Figure 4). The associated etiological factors include poor oral hygiene practice, nocturnal denture wear, ill-fitting prostheses and limited flow of saliva (Farah et al., 2010; Williams and Lewis, 2011).

\section{Angular cheilitis}

This form of candidiasis usually manifests as erythematous or ulcerated fissures, typically affecting unilaterally or bilaterally the commissures of the lip (Samaranayake et al., 1995; Sharon and Fazel, 2010). Angular cheilitis often represents an opportunistic infection of fungi and/or bacteria, with multiple local and systemic predisposing factors involved in the initiation and persistence of the lesion (Park et al., 2011). The factors associated include old age and denture-wearers (due to reduced vertical dimension), vitamin B12 deficiency and iron deficiency anemia (Jenkins et al., 1977). Other causative organisms implicated are Staphylococcus and Streptococcus (Farah et al., 2010).

\section{Median rhomboid glossitis}

Median rhomboid glossitis appears as the central papillary atrophy of the tongue and is typically located around the midline of the dorsum of the tongue. It occurs as a well-demarcated, symmetric, depapillated area arising anterior to the circumvallate papillae (Figure 5). The surface of the lesion can be smooth or lobulated (Joseph and Savage, 2000). While most of the cases are asymptomatic, some patients complain of persistent pain, irritation, or pruritus (Lago-Mendez et al., 2005). The lesion is now believed to be a localized chronic infection by $C$. albicans. It is commonly seen in tobacco smokers and inhalation-steroid users (Aun et al., 2009; Williams and Lewis, 2011).

\section{Linear gingival erythema}

It was previously referred to as "HIV-gingivitis" since its typical occurrence was in HIV associated periodontal diseases (Figure 6). It manifests as linear erythematous band of 2$3 \mathrm{~mm}$ on the marginal gingiva along with petechial or diffuse erythematous lesions on the attached gingiva. The lesions may present with bleeding. In addition to C. albicans, C. dubliniensis

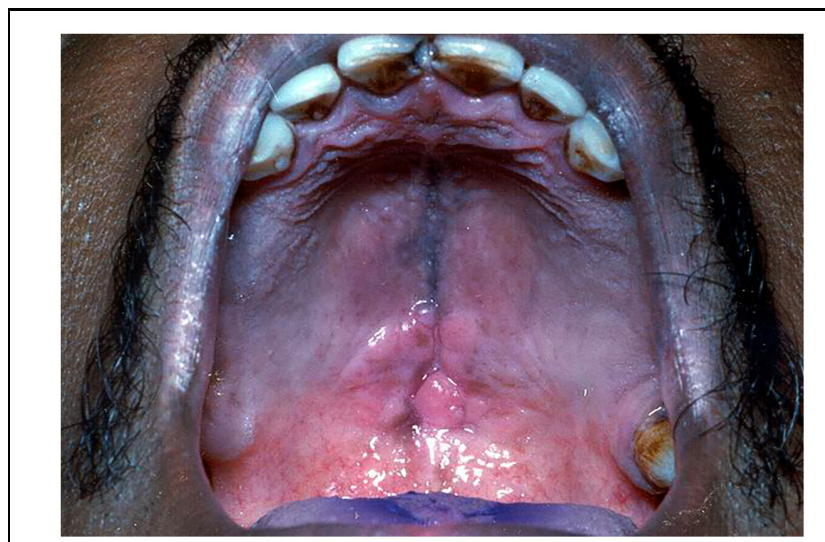

FIGURE 4 | Denture stomatitis of the palate.

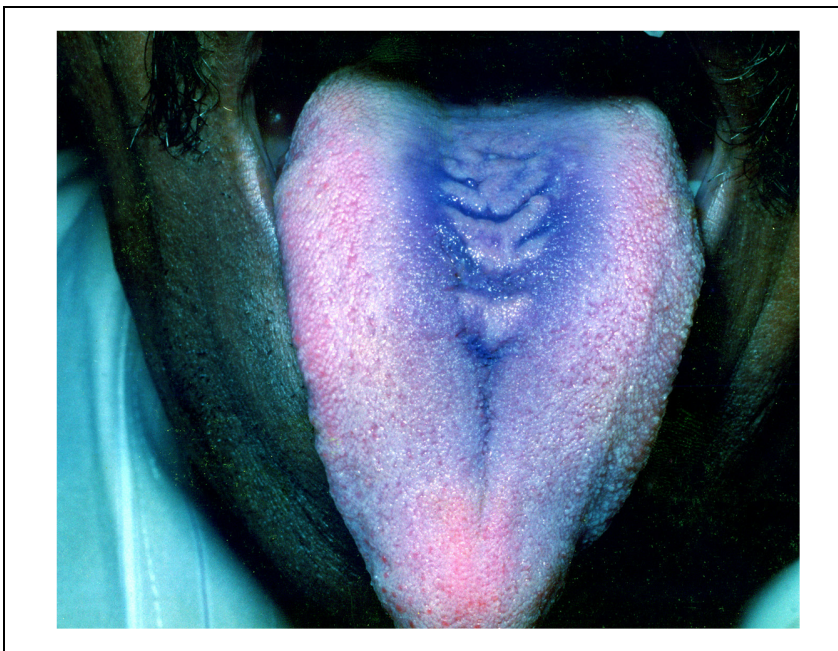

FIGURE 5 | Median Rhomboid glossitis-note the candidal overgrowth.

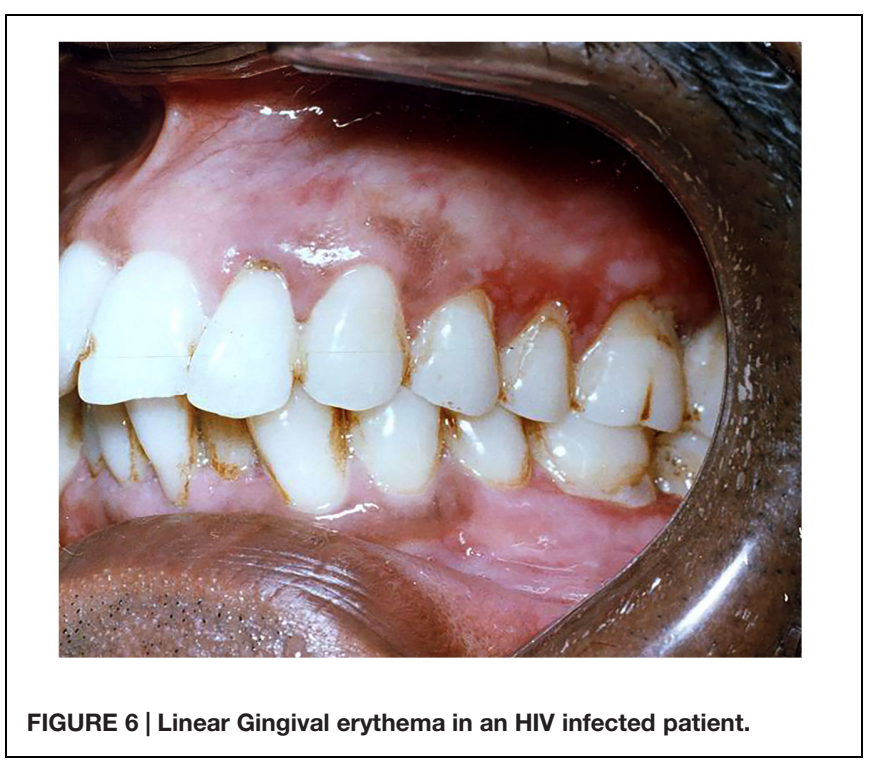

has been reported as an emerging pathogen in this form of candidiasis (Williams and Lewis, 2011).

\section{Secondary Oral Candidiasis}

This group is characterized by chronic mucocutaneous candidiasis, which consists of heterogeneous disorders, presenting as persistent or recurrent superficial candida infections of the mouth, skin, nail beds, and occasionally producing granulomatous masses over the face and scalp. The primary clinical features include chronic oral, cutaneous and vulvovaginal candidiasis. Oral cavity involvement is reported in more than $90 \%$ cases and the lesions can occasionally spread into the larynx, pharynx or esophagus but further involvement is infrequent. It is associated with diverse immunodeficiency disorders such as, Di George syndrome, hyper-immunoglobulin E syndrome, Nezelof's syndrome MPO deficiency, SCID syndrome and endocrine disorders like Addison's disease and 
hypoparathyroidism (Ashman and Farah, 2005; Farah et al., 2010; Williams and Lewis, 2011; Lalla et al., 2013).

\section{ORAL CANDIDA INFECTION IN NEWBORNS}

Oral candidiasis in neonates is reported to be $0.5-20 \%$, depending upon the various studies (Yilmaz et al., 2011; Stecksen-Blicks et al., 2015). The most common form of candidiasis affecting this age group is the acute pseudomembranous candidiasis (Berdicevsky et al., 1984). Candida species isolated from these lesions include C. albicans, followed by C. glabrata, C. tropicalis and C. krusei (Tinoco-Araujo et al., 2013). Majority of the lesions are asymptomatic. They mainly present as white scrapable pseudomembranous lesions. The major predisposing factors were low birth weight, prolonged hospital stay and associated increased risk of exposure to environmental factors. The participation of dental surgeon is essential in early diagnosis of the oral signs and symptoms of this opportunistic infection in order to prevent disseminated candidiasis and subsequent mortality (2-20\%; Sitheeque and Samaranayake, 2003). Treatment for superficial infection is topical administration of antifungals such as $1 \%$ clotrimazole solution thrice daily for 7 days. In case of invasive or disseminated candidiasis, systemic interventions are obligatory (Sitheeque and Samaranayake, 2003).

\section{MANAGEMENT OF ORAL CANDIDOSIS}

An effective management of oral candidiasis can be achieved by adhering to the following simple guidelines:

(1) Diagnosis through detailed medical and dental history, clinical manifestations confirmed with laboratory tests.

(2) Correction of predisposing factors where achievable.

(3) Maintenance of proper hygiene of the oral cavity and oral prostheses, if any.

(4) Selection of antifungal therapy based on severity of the infection and susceptibility of the Candida species prevalent in that patient.

Diagnosis of oral candidosis, includes identification of clinical signs and symptoms, presence of the candida organisms on direct examination of a smear from the lesion or biopsy examination showing hyphae in the epithelium, positive culture, and serological tests (Rossie and Guggenheimer, 1997; Ellepola and Morrison, 2005). Another concern with respect to the treatment, is the increase in NCAC species which are naturally resistant to some of the common antifungal drugs (Table 4). For example, in HIV positive cases there is reported increase in C. glabrata, followed by C. krusei; in insulin using diabetes mellitus patients' significant percentage of C. dubliniensis and C. glabrata was noted; also certain mucosal lesions, oral cancer and elderly hospitalized patients have shown increase in NCAC species carriage (Gutierrez et al., 2002).

\section{ANTIFUNGAL AGENTS}

Antifungal agents that are available for the treatment of candidosis fall into three main categories: the polyenes (nystatin and amphotericin B); the ergosterol biosynthesis inhibitorsthe azoles (miconazole, clotrimazole, ketoconazole, itraconazole, and fluconazole), allylaminesthiocarbamates, and morpholines; and DNA analog 5-fluorocytosine, and newer agents such as caspofungins (Ghannoum and Rice, 1999; Pappas et al., 2009). The choice of antifungal treatment depends on the nature of the lesion and the immunological status of the patient. There are three main antifungal drug targets in Candida: the cell membrane, cell wall, and nucleic acids (Figure 7) (Cannon et al., 2007).

Superficial oral candidosis in generally healthy patients can be treated topically and oral candidosis in immunocompromised patients should be treated systemically as well as topically. Patients with persisting risk factors and relapsing candidosis should be treated with antifungals with the lowest risk of development or selection of resistant strains (Soysa et al., 2008; Rautemaa and Ramage, 2011). The commonly used antifungal agents in the management of OPC is listed in Table 5.

\section{TOPICAL ANTIFUNGALS}

Topical antifungals are usually the drug of choice for uncomplicated, localized candidiasis in patients with normal immune function. High levels can be achieved in the oral epithelium with topically administered antifungals. Polyenes are fungicidal drugs that act through direct binding to the ergosterol within the fungal cell membranes, inducing leakage

TABLE 4 | Susceptibility of C. albicans and common NCAC species (Gutierrez et al., 2002; Pappas et al., 2009).

\begin{tabular}{|c|c|c|c|c|c|}
\hline Candida species & Fluconazole & Itraconazole & Amphotericin B & Echinocandin & Flucytosine \\
\hline Candida albicans & S & S & S & $S$ & $S$ \\
\hline Candida tropicalis & S & S & S & S & S \\
\hline Candida glabrata & S-DD to $R$ & S-DD to $R$ & S-1 & S & S \\
\hline Candida krusei & $\mathrm{R}$ & S-DD to $R$ & S to S-I & S & S-I to R \\
\hline Candida dubliniensis & S to $R$ & $S$ to $R$ & $S$ & $S$ & $S$ \\
\hline
\end{tabular}

S, Susceptible; S-DD, Susceptible dose-dependent; S-I, Susceptible intermediate; R, Resistant. 


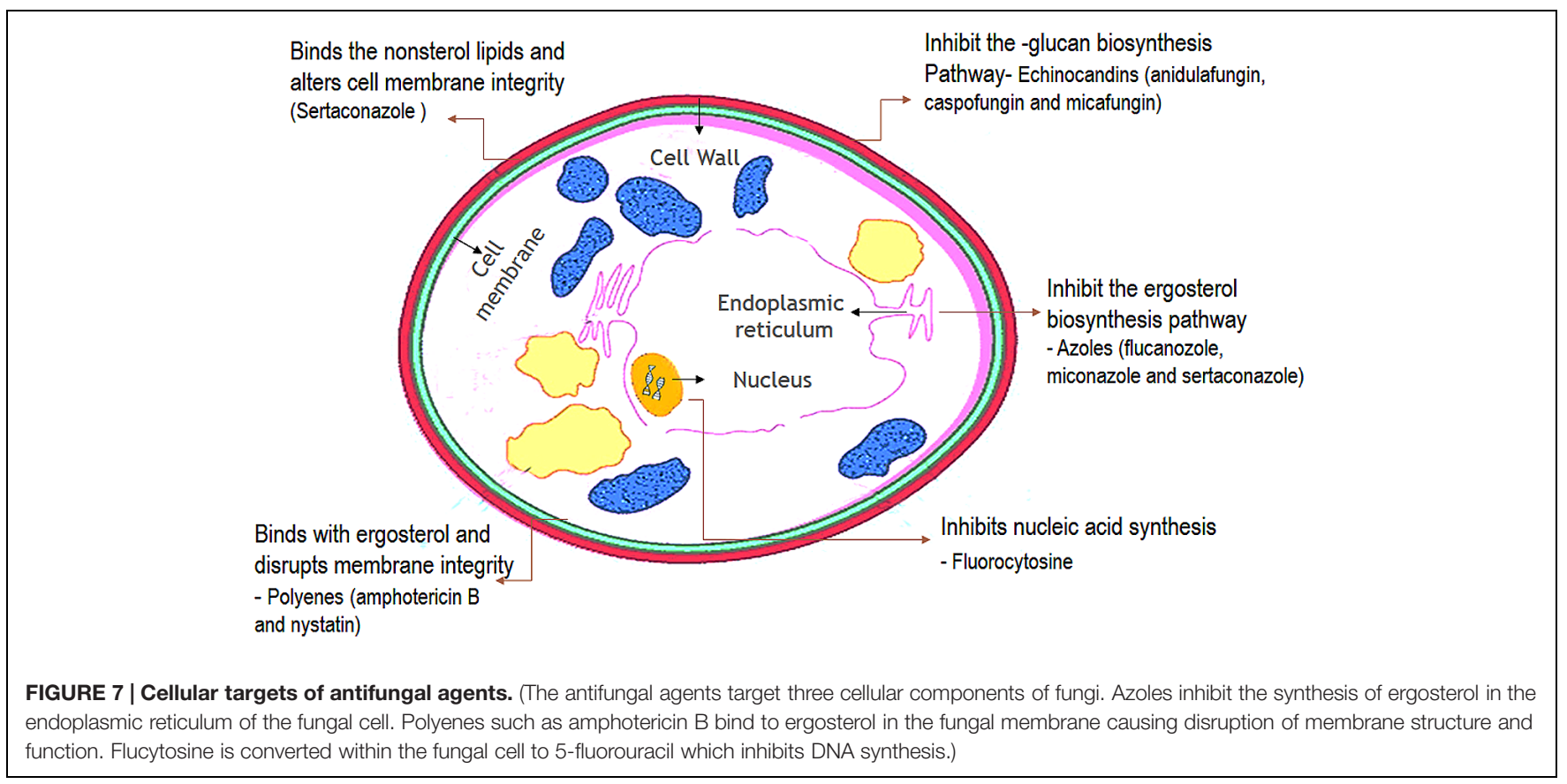

TABLE 5 | Treatment of oropharyngeal candidiasis (OPC; Thompson et al., 2010).

\begin{tabular}{lll}
\hline Severity & Antifungal drug & Dosage/ Duration \\
\hline First-line agents & & $100-200 \mathrm{mg} / 7-14$ days \\
& Fluconazole (PO or IV) & $10 \mathrm{mg}$ five times/7-14 days \\
Second-line agents & Clotrimazole troches & $4-6 \mathrm{ml}$ four times/7-14 days \\
& Nystatin suspension (100,000 U/mL) & $1-2$ pastilles four times/7-14 days \\
Agents used in refractory case of OPC & Itraconazole solution (PO) & $200 \mathrm{mg} / 28$ days \\
& Posaconazole (PO) & $400 \mathrm{mg}$ daily in divided doses \\
& Voriconazole (PO or IV) & $200 \mathrm{mg}$ twice daily \\
& Caspofungin (IV) & $70 \mathrm{mg}$ loading dose followed by $50 \mathrm{mg}$ daily \\
& Micafungin (IV) & $100-150 \mathrm{mg}$ daily \\
& Anidulafungin (IV) & $100 \mathrm{mg}$ loading dose followed by $50 \mathrm{mg}$ daily \\
& Amphotericin B oral suspension & $500 \mathrm{mg}$ every $6 \mathrm{~h}$ \\
\end{tabular}

of cytoplasmic contents leading to the fungal cell death. Nystatin or amphotericin B solutions are used for 4 weeks. In recurrent cases the duration of treatment should be for at least 4-6 weeks.

Topically administered miconazole gel is also suitable for the treatment of uncomplicated infections in generally healthy patients (Bensadoun et al., 2008). It should also be used for 1 week after resolution of symptoms. The gel inhibits the action of fungal ergosterol synthesis; interacts with the cytochrome P450 enzyme 14-alpha demethylase; inhibits growth of pathogenic yeasts by altering cell membrane permeability. Repeated use of miconazole, however, may cause a risk of development of azole-resistant strains (Rautemaa et al., 2008).

\section{SYSTEMIC ANTIFUNGALS}

Systemic antifungals are usually indicated in cases of disseminated disease and/or in immunocompromised patients. Azoles are fungistatic drugs that inhibit the fungal enzyme lanosterol demethylase responsible for the synthesis of ergosterol. Among the azoles, fluconazole attains a higher concentration in the saliva making it principally the suitable drug for treating this oral infection. Fluconazole and itraconazole are administered orally and it gets secreted onto mucous membranes. The oral solution also has a topical effect (Pappas et al., 2004). The other antifungals, echinocandins, and flucytosine act through inhibition of D-glucan synthase and DNA/protein synthesis, respectively (Muir et al., 2009; Vandeputte et al., 2012). 
Posaconazole, is available only as an oral solution and is used in immunocompromised patients and patients resistant to other drugs (Clark et al., 2015).

One of the risks while using fluconazole and other drugs of the azole group is the development of resistant strains (Siikala et al., 2010). For fluconazole-refractory disease, either itraconazole solution at a dosage of $200 \mathrm{mg}$ daily or posaconazole suspension at a dosage of $400 \mathrm{mg}$ twice daily for 3 days, then $400 \mathrm{mg}$ daily for up to 28 days, are recommended. Voriconazole at a dosage of $200 \mathrm{mg}$ twice daily or a $1-\mathrm{mL}$ oral suspension of AmB-d, administered at a dosage of $100 \mathrm{mg} / \mathrm{mL}$ four times daily, are recommended when treatment with other agents has failed. Intravenous echinocandin or AmB-d at a dosage of $0.3 \mathrm{mg} / \mathrm{kg}$ daily can be used in treating patients with refractory disease (Vazquez, 2003).

\section{ALTERNATIVE ANTI CANDIDAL AGENTS}

Lastly, to mention a few natural anti-yeast substances which can be used as an alternative treatment. These agents with recognized activity against $C$. albicans includes berberine-containing plants; caprylic acid; grapefruit seed extract; garlic; probiotics; tea tree oil and enteric-coated volatile oil preparations containing cinnamon, ginger, oregano, peppermint and rosemary; propolis and thyme (Hofling et al., 2010; Valera et al., 2013). Agents capable of inhibiting microbial growth such as xylitol is known to inhibit microbial metabolism in the oral cavity. It is therefore incorporated in chewing gums and tablets as well as in health care products such as dentifrice and oral rinses. Although it has a limited effect on Candida, it could be beneficial in prevention of the mixed biofilm infection (Pizzo et al., 2000). The essential oil of Melaleuca alternifolia, also known as tea tree oil has been shown to be promising as a topical antifungal agent, with recent clinical data indicating efficacy in the treatment of oral candidiasis (Hammer et al., 2004; Sitheeque et al., 2009).

\section{REFERENCES}

Akpan, A., and Morgan, R. (2002). Oral candidiasis. Postgrad. Med. J. 78, 455-459. doi: $10.1136 / \mathrm{pmj} .78 .922 .455$

Anil, S., and Challacombe, S. J. (1997). Oral lesions of HIV and AIDS in Asia: an overview. Oral Dis. 3(Suppl. 1), S36-S40. doi: 10.1111/j.16010825.1997.tb00371.x

Arendorf, T. M., and Walker, D. M. (1980). The prevalence and intra-oral distribution of Candida albicans in man. Arch. Oral Biol. 25, 1-10. doi: 10.1016/0003-9969(80)90147-8

Arendorf, T. M., and Walker, D. M. (1987). Denture stomatitis: a review. J. Oral Rehabil. 14, 217-227. doi: 10.1111/j.1365-2842.1987. tb00713.x

Ashman, R. B., and Farah, C. S. (2005). "Oral candidiasis: clinical manifestations and cellular adaptive host responses," in Fungal Immunology, eds P. L. Fidel and G. B. Huffnagle (New York, NY: Springer), 59-83.

Aun, M. V., Ribeiro, M. R., Costa Garcia, C. L., Agondi, R. C., Kalil, J., and Giavina-Bianchi, P. (2009). Esophageal candidiasis-an adverse effect of inhaled corticosteroids therapy. J. Asthma 46, 399-401. doi: $10.1080 / 02770900902777783$

\section{PREVENTION OF ORAL CANDIDOSIS}

Good oral hygiene practices may help to prevent oral thrush in people with weakened immune systems. Careful mechanical cleaning of teeth and dentures with a toothbrush is the cornerstone of the prevention of candida infections. Oral decontamination using antifungal and antibacterial rinses is one of the approaches often used to manage oral mucositis (Fathilah et al., 2012). Chlorhexidine digluconate, and cetylpyridinium chloride are two antiseptics often incorporated in mouth rinses and used as prophylaxis for both chemotherapy and radiotherapy induced mucositis (Salim et al., 2013). People who use inhaled corticosteroids may be able to reduce the risk of developing thrush by washing out the mouth with water or mouthwash after using an inhaler (Soares et al., 2011). For susceptible denture wearers, it is advisable to remove the denture at night and soak in $0.2 \%$ Chlorhexidine solution or $15-30 \mathrm{~min}$ in white vinegar (diluted $1: 20$ ) or $0.1 \%$ hypochlorite solution (Kassaify et al., 2008). The elimination or at least regulation of the predisposing factors for candidiasis is essential. Failure to recognize this may only provide a temporary relief using antifungal therapy, but with inevitable relapse of the infection (Akpan and Morgan, 2002).

\section{CONCLUSION}

In the past few decades extensive clinical data has been recorded on oral candidiasis with respect to its advent with the various immunocompromised conditions. With the increasing incidence of NCAC species and the development of antifungal resistance, there is a persistent requirement in research for newer effective agents. One such prospect is development of vaccine against candida organisms. Various experimental strategies have been employed for developing such a vaccine, like attenuated live candida organisms, SAP gene family proteins, glycoconjugates (mannans and $\beta$-glucans) to mention a few, but clinical trials are still a distant vision.

Axell, T., Samaranayake, L. P., Reichart, P. A., and Olsen, I. (1997). A proposal for reclassification of oral candidosis. Oral Surg. Oral Med. Oral Pathol. Oral Radiol. Endod. 84, 111-112. doi: 10.1016/S1079-2104(97)90049-4

Bakker, R. C., Gallas, P. R., Romijn, J. A., and Wiersinga, W. M. (1998). Cushing's syndrome complicated by multiple opportunistic infections. J. Endocrinol. Invest. 21, 329-333. doi: 10.1007/BF03350337

Barnett, J. A. (2008). A history of research on yeasts 12: medical yeasts part 1, Candida albicans. Yeast 25, 385-417. doi: 10.1002/yea.1595

Bensadoun, R. J., Daoud, J., El Gueddari, B., Bastit, L., Gourmet, R., Rosikon, A., et al. (2008). Comparison of the efficacy and safety of miconazole 50mg mucoadhesive buccal tablets with miconazole 500-mg gel in the treatment of oropharyngeal candidiasis: a prospective, randomized, singleblind, multicenter, comparative, phase III trial in patients treated with radiotherapy for head and neck cancer. Cancer 112, 204-211.

Berdicevsky, I., Ben-Aryeh, H., Szargel, R., and Gutman, D. (1984). Oral Candida in children. Oral Surg. Oral Med. Oral Pathol. 57, 37-40. doi: 10.1016/00304220(84)90257-3

Cannon, R. D., Lamping, E., Holmes, A. R., Niimi, K., Tanabe, K., Niimi, M., et al. (2007). Candida albicans drug resistance another way to cope with stress. Microbiology 153, 3211-3217. doi: 10.1099/mic.0.2007/010405-0 
Clark, N. M., Grim, S. A., and Lynch, J. P. I. I. I. (2015). Posaconazole: use in the prophylaxis and treatment of fungal infections. Semin. Respir. Crit. Care Med. 36, 767-785. doi: 10.1055/s-0035-1562902

Crist, A. E. Jr., Johnson, L. M., and Burke, P. J. (1996). Evaluation of the Microbial Identification System for identification of clinically isolated yeasts. J. Clin. Microbiol. 34, 2408-2410.

Dodd, C. L., Greenspan, D., Katz, M. H., Westenhouse, J. L., Feigal, D. W., and Greenspan, J. S. (1991). Oral candidiasis in HIV infection: pseudomembranous and erythematous candidiasis show similar rates of progression to AIDS. AIDS 5, 1339-1343. doi: 10.1097/00002030-199111000-00009

Ellepola, A. N., and Morrison, C. J. (2005). Laboratory diagnosis of invasive candidiasis. J. Microbiol. 43, 65-84.

Farah, C. S., Lynch, N., and Mccullough, M. J. (2010). Oral fungal infections: an update for the general practitioner. Aust. Dent. J. 55(Suppl. 1), 48-54. doi: 10.1111/j.1834-7819.2010.01198.x

Fathilah, A. R., Himratul-Aznita, W. H., Fatheen, A. R., and Suriani, K. R. (2012). The antifungal properties of chlorhexidine digluconate and cetylpyrinidinium chloride on oral Candida. J. Dent. 40, 609-615. doi: 10.1016/j.jdent.2012.04.003

Ghannoum, M. A., and Rice, L. B. (1999). Antifungal agents: mode of action, mechanisms of resistance, and correlation of these mechanisms with bacterial resistance. Clin. Microbiol. Rev. 12, 501-517.

Graham, B. S., and Tucker, W. S. Jr. (1984). Opportunistic infections in endogenous Cushing's syndrome. Ann. Intern. Med. 101, 334-338. doi: 10.7326/0003-4819101-3-334

Gutierrez, J., Morales, P., Gonzalez, M. A., and Quindos, G. (2002). Candida dubliniensis, a new fungal pathogen. J. Basic Microbiol. 42, 207-227. doi: 10.1002/1521-4028(200206)42:3<207::AID-JOBM207>3.0.CO;2-C

Hammer, K. A., Carson, C. F., and Riley, T. V. (2004). Antifungal effects of Melaleuca alternifolia (tea tree) oil and its components on Candida albicans, Candida glabrata and Saccharomyces cerevisiae. J. Antimicrob. Chemother. 53, 1081-1085. doi: 10.1093/jac/dkh243

Hofling, J. F., Anibal, P. C., Obando-Pereda, G. A., Peixoto, I. A., Furletti, V. F., Foglio, M. A., et al. (2010). Antimicrobial potential of some plant extracts against Candida species. Braz. J. Biol. 70, 1065-1068. doi: 10.1590/S151969842010000500022

Holmstrup, P., and Bessermann, M. (1983). Clinical, therapeutic, and pathogenic aspects of chronic oral multifocal candidiasis. Oral Surg. Oral Med. Oral Pathol. 56, 388-395. doi: 10.1016/0030-4220(83)90349-3

Hsia, C. C., Sun, T. T., Wang, Y. Y., Anderson, L. M., Armstrong, D., and Good, R. A. (1981). Enhancement of formation of the esophageal carcinogen benzylmethylnitrosamine from its precursors by Candida albicans. Proc. Natl. Acad. Sci. U.S.A. 78, 1878-1881. doi: 10.1073/pnas.78.3.1878

Jainkittivong, A., Kuvatanasuchati, J., Pipattanagovit, P., and Sinheng, W. (2007). Candida in oral lichen planus patients undergoing topical steroid therapy. Oral Surg. Oral Med. Oral Pathol. Oral Radiol. Endod. 104, 61-66. doi: 10.1016/j.tripleo.2006.10.024

Jenkins, W. M., Macfarlane, T. W., Ferguson, M. M., and Mason, D. K. (1977). Nutritional deficiency in oral candidosis. Int. J. Oral Surg. 6, 204-210. doi: 10.1016/S0300-9785(77)80010-0

Joseph, B. K., and Savage, N. W. (2000). Tongue pathology. Clin. Dermatol. 18, 613-618. doi: 10.1016/S0738-081X(00)00137-1

Kassaify, Z., Gerges, D. D., Jaber, L. S., Hamadeh, S. K., Aoun Saliba, N., Talhouk, S. N., et al. (2008). Bioactivity of origanum syriacum essential oil against Candida albicans. J. Herbs Spices Med. Plants 14, 185-199. doi: 10.1080/10496470802598818

Krogh, P., Hald, B., and Holmstrup, P. (1987). Possible mycological etiology of oral mucosal cancer: catalytic potential of infecting Candida albicans and other yeasts in production of N-nitrosobenzylmethylamine. Carcinogenesis 8, 1543-1548. doi: 10.1093/carcin/8.10.1543

Lago-Mendez, L., Blanco-Carrion, A., Diniz-Freitas, M., Gandara-Vila, P., GarciaGarcia, A., and Gandara-Rey, J. M. (2005). Rhomboid glossitis in atypical location: case report and differential diagnosis. Med. Oral Patol. Oral Cir. Bucal 10, 123-127.

Lalla, R. V., Patton, L. L., and Dongari-Bagtzoglou, A. (2013). Oral candidiasis: pathogenesis, clinical presentation, diagnosis and treatment strategies. J. Calif. Dent. Assoc. 41, 263-268.

Lund, R. G., Da Silva Nascente, P., Etges, A., Ribeiro, G. A., Rosalen, P. L., and Del Pino, F. A. (2010). Occurrence, isolation and differentiation of Candida spp. and prevalence of variables associated to chronic atrophic candidiasis. Mycoses 53, 232-238. doi: 10.1111/j.1439-0507.2009.01697.x

Martins, N., Ferreira, I. C., Barros, L., Silva, S., and Henriques, M. (2014). Candidiasis: predisposing factors, prevention, diagnosis and alternative treatment. Mycopathologia 177, 223-240. doi: 10.1007/s11046-014-9749-1

Martori, E., Ayuso-Montero, R., Martinez-Gomis, J., Vinas, M., and Peraire, M. (2014). Risk factors for denture-related oral mucosal lesions in a geriatric population. J. Prosthet. Dent. 111, 273-279. doi: 10.1016/j.prosdent.2013.07.015

Muir, A., Jenkins, A. T., Forrest, G., Clarkson, J., and Wheals, A. (2009). Rapid electrochemical identification of pathogenic Candida species. J. Med. Microbiol. 58, 1182-1189. doi: 10.1099/jmm.0.009183-0

Munshi, T., Heckman, C. J., and Darlow, S. (2015). Association between tobacco waterpipe smoking and head and neck conditions: a systematic review. J. Am. Dent. Assoc. 146, 760-766. doi: 10.1016/j.adaj.2015.04.014

Owotade, F. J., and Patel, M. (2014). Virulence of oral Candida isolated from HIV-positive women with oral candidiasis and asymptomatic carriers. Oral Surg. Oral Med. Oral Pathol. Oral Radiol. 118, 455-460. doi: 10.1016/j.0ooo.2014.07.004

Paillaud, E., Merlier, I., Dupeyron, C., Scherman, E., Poupon, J., and Bories, P. N. (2004). Oral candidiasis and nutritional deficiencies in elderly hospitalised patients. Br. J. Nutr. 92, 861-867. doi: 10.1079/BJN20041264

Pappas, P. G., Kauffman, C. A., Andes, D., Benjamin, D. K. Jr., Calandra, T. F., Edwards, J. E. Jr., et al. (2009). Clinical practice guidelines for the management of candidiasis: 2009 update by the Infectious Diseases Society of America. Clin. Infect. Dis. 48, 503-535. doi: 10.1086/596757

Pappas, P. G., Rex, J. H., Sobel, J. D., Filler, S. G., Dismukes, W. E., Walsh, T. J., et al. (2004). Guidelines for treatment of candidiasis. Clin. Infect. Dis. 38, 161-189. doi: 10.1086/380796

Park, K. K., Brodell, R. T., and Helms, S. E. (2011). Angular cheilitis, part 2: nutritional, systemic, and drug-related causes and treatment. Cutis 88, 27-32.

Pizzo, G., Giuliana, G., Milici, M. E., and Giangreco, R. (2000). Effect of dietary carbohydrates on the in vitro epithelial adhesion of Candida albicans, Candida tropicalis, and Candida krusei. New Microbiol. 23, 63-71.

Rautemaa, R., and Ramage, G. (2011). Oral candidosis-clinical challenges of a biofilm disease. Crit. Rev. Microbiol. 37, 328-336. doi: 10.3109/1040841X.2011.585606

Rautemaa, R., Richardson, M., Pfaller, M., Perheentupa, J., and Saxen, H. (2008). Reduction of fluconazole susceptibility of Candida albicans in APECED patients due to long-term use of ketoconazole and miconazole. Scand. J. Infect. Dis. 40, 904-907. doi: 10.1080/00365540802275853

Richardson, M. D. (2005). Changing patterns and trends in systemic fungal infections. J. Antimicrob. Chemother. 56(Suppl. 1), i5-i11. doi: $10.1093 /$ jac/dki218

Rossie, K., and Guggenheimer, J. (1997). Oral candidiasis: clinical manifestations, diagnosis, and treatment. Pract. Periodontics Aesthet. Dent. 9, 635-641; quiz 642.

Salim, N., Moore, C., Silikas, N., Satterthwaite, J., and Rautemaa, R. (2013). Chlorhexidine is a highly effective topical broad-spectrum agent against Candida spp. Int. J. Antimicrob. Agents 41, 65-69. doi: 10.1016/j.ijantimicag.2012.08.014

Samaranayake, L. P., Wilkieson, C. A., Lamey, P. J., and Macfarlane, T. W. (1995). Oral disease in the elderly in long-term hospital care. Oral Dis. 1, 147-151. doi: 10.1111/j.1601-0825.1995.tb00177.x

Sanketh, D. S., Patil, S., and Rao, R. S. (2015). Estimating the frequency of Candida in oral squamous cell carcinoma using Calcofluor White fluorescent stain. J. Investig. Clin. Dent. doi: 10.1111/jicd.12161 [Epub ahead of print].

Sashikumar, R., and Kannan, R. (2010). Salivary glucose levels and oral candidal carriage in type II diabetics. Oral Surg. Oral Med. Oral Pathol. Oral Radiol. Endod. 109, 706-711. doi: 10.1016/j.tripleo.2009.12.042

Scheffel, R. S., Dora, J. M., Weinert, L. S., Aquino, V., Maia, A. L., Canani, L. H., et al. (2010). Invasive fungal infections in endogenous Cushing's syndrome. Infect. Dis. Rep. 2, e4. doi: 10.4081/idr.2010.e4

Scully, C., El-Kabir, M., and Samaranayake, L. P. (1994). Candida and oral candidosis: a review. Crit. Rev. Oral Biol. Med. 5, 125-157.

Sharon, V., and Fazel, N. (2010). Oral candidiasis and angular cheilitis. Dermatol. Ther. 23, 230-242. doi: 10.1111/j.1529-8019.2010.01320.x

Sherman, R. G., Prusinski, L., Ravenel, M. C., and Joralmon, R. A. (2002). Oral candidosis. Quintessence Int. 33, 521-532. 
Siikala, E., Rautemaa, R., Richardson, M., Saxen, H., Bowyer, P., and Sanglard, D. (2010). Persistent Candida albicans colonization and molecular mechanisms of azole resistance in autoimmune polyendocrinopathy-candidiasis-ectodermal dystrophy (APECED) patients. J. Antimicrob. Chemother. 65, 2505-2513. doi: 10.1093/jac/dkq354

Sitheeque, M. A., Panagoda, G. J., Yau, J., Amarakoon, A. M., Udagama, U. R., and Samaranayake, L. P. (2009). Antifungal activity of black tea polyphenols (catechins and theaflavins) against Candida species. Chemotherapy 55, 189-196. doi: $10.1159 / 000216836$

Sitheeque, M. A., and Samaranayake, L. P. (2003). Chronic hyperplastic candidosis/candidiasis (candidal leukoplakia). Crit. Rev. Oral Biol. Med. 14, 253-267. doi: 10.1177/154411130301400403

Soares, A. F., Aquino, A. R., Carvalho, C. H., Nonaka, C. F., Almeida, D., and Pinto, L. P. (2011). Frequency of oral mucositis and microbiological analysis in children with acute lymphoblastic leukemia treated with $0.12 \%$ chlorhexidine gluconate. Braz. Dent. J. 22, 312-316. doi: 10.1590/S0103-64402011000400009

Soysa, N. S., and Ellepola, A. N. (2005). The impact of cigarette/tobacco smoking on oral candidosis: an overview. Oral Dis. 11, 268-273. doi: 10.1111/j.16010825.2005.01115.x

Soysa, N. S., Samaranayake, L. P., and Ellepola, A. N. (2008). Antimicrobials as a contributory factor in oral candidosis-a brief overview. Oral Dis. 14, 138-143. doi: 10.1111/j.1601-0825.2006.01357.x

Stecksen-Blicks, C., Granstrom, E., Silfverdal, S. A., and West, C. E. (2015). Prevalence of oral Candida in the first year of life. Mycoses 58, 550-556. doi: 10.1111/myc.12355

Thompson, G. R. III, Patel, P. K., Kirkpatrick, W. R., Westbrook, S. D., Berg, D., Erlandsen, J., et al. (2010). Oropharyngeal candidiasis in the era of antiretroviral therapy. Oral Surg. Oral Med. Oral Pathol. Oral Radiol. Endod. 109, 488-495. doi: 10.1016/j.tripleo.2009.11.026

Tinoco-Araujo, J. E., Araujo, D. F., Barbosa, P. G., Santos, P. S., and Medeiros, A. M. (2013). Invasive candidiasis and oral manifestations in premature newborns. Einstein (Sao Paulo) 11, 71-75. doi: 10.1590/S167945082013000100013
Turner, M. D., and Ship, J. A. (2007). Dry mouth and its effects on the oral health of elderly people. J. Am. Dent. Assoc. 138(Suppl.), 15S-20S. doi: 10.14219/jada.archive.2007.0358

Valera, M. C., Maekawa, L. E., De Oliveira, L. D., Jorge, A. O., Shygei, E., and Carvalho, C. A. (2013). In vitro antimicrobial activity of auxiliary chemical substances and natural extracts on Candida albicans and Enterococcus faecalis in root canals. J. Appl. Oral Sci. 21, 118-123. doi: 10.1590/1678-7757201 302135

Vandeputte, P., Ferrari, S., and Coste, A. T. (2012). Antifungal resistance and new strategies to control fungal infections. Int. J. Microbiol. 2012, 713687. doi: $10.1155 / 2012 / 713687$

Vazquez, J. A. (2003). Invasive oesophageal candidiasis: current and developing treatment options. Drugs 63, 971-989. doi: 10.2165/00003495-20036310000004

Weerasuriya, N., and Snape, J. (2008). Oesophageal candidiasis in elderly patients: risk factors, prevention and management. Drugs Aging 25, 119-130. doi: 10.2165/00002512-200825020-00004

Williams, D., and Lewis, M. (2011). Pathogenesis and treatment of oral candidosis. J. Oral Microbiol. 3, 5771. doi: 10.3402/jom.v3i0.5771

Yilmaz, A. E., Gorpelioglu, C., Sarifakioglu, E., Dogan, D. G., Bilici, M., and Celik, N. (2011). Prevalence of oral mucosal lesions from birth to two years. Niger. J. Clin. Pract. 14, 349-353. doi: 10.4103/1119-3077.86782

Conflict of Interest Statement: The authors declare that the research was conducted in the absence of any commercial or financial relationships that could be construed as a potential conflict of interest.

Copyright (C) 2015 Patil, Rao, Majumdar and Anil. This is an open-access article distributed under the terms of the Creative Commons Attribution License (CC BY). The use, distribution or reproduction in other forums is permitted, provided the original author(s) or licensor are credited and that the original publication in this journal is cited, in accordance with accepted academic practice. No use, distribution or reproduction is permitted which does not comply with these terms. 